\title{
2. THE RELEVANCE OF BIOGRAPHICAL STUDIES FOR EMPOWERMENT STRATEGIES
}

\section{INTRODUCTION}

Although it is common sense that women's work is influenced by globalization processes, their socio-psychological impact is scarcely investigated. Little attention is paid to the subjective implications of the notion "women's work as an ensemble of different forms of practices". The personal importance of the combination of domestic and professional work is, so to speak, "a dark continent". Are the experiences women make with different forms of work either positive or negative or do we have to anticipate an emotional entanglement of attraction and defense? In addition: we don't know very much about the psychic energy that women have to summon when they are forced to give up routinized balances. That is necessary, when shifts within the labor-market alter women's work under the pressure of worldwide economic competition.

Before I present a socio-psychological approach, which throws light on the inner dynamic of women's working experiences, I want to make some brief preliminary remarks. I think that insights into the feelings and perceptions of women, concerning their working conditions as a whole, are relevant for discussing adequate empowerment strategies. Women who switch from domestic (subsistence) work to market mediated work and back again are confronted with challenges, conflicts and constraints which men don't have to bear in the same way. Disadvantages women suffer due to their gender are not only based on unjust distribution of paid and unpaid work, but also on a disrespect of the psychological burden resulting from their multiorientation which tries to integrate both family subsistence and professional career. The neglect of their physical and psychological exertions belongs to the indifference which characterizes andro-centric or patriarchal gender orders which is accompanied by a disregard for human needs in the capitalist organization of work. If we want to understand women as vulnerable and simultaneously steady subjects, who are willing to fight for their rights, we have to acknowledge their biographies as processes of lifelong learning. But lifelong learning for me does not only mean always having skills in the newest standards of know-how, above all technological know-how, but also not forgetting cultural achievements, human claims and personal dreams. At the risk of being diminished by economic rationalization these dimensions must always be revitalized. 
We have to be aware that women bridge what is societally divided - the public and the private sphere as well as productive, reproductive and regenerative activities. This recombining of the separated social practices takes place in an invisible and silent way. There is no public discourse articulating women's efforts and the efficiencies of these efforts for society. Empowerment activities can make both the burden and the social value of this knotting of divided sectors transparent. This knotting guarantees the maintenance of social life.

That is for me the frame of a political psychology and sociology with practical ambitions, in which the investigation of female biographical studies should be embedded.

\section{SPECIFIC CONFLICTS IN WOMEN'S ENSEMBLE OF WORK}

From a feminist perspective, analyzing women's work biographies has not only to do with objective life conditions, but also with the conflicts which shape experiences. That is especially important for the understanding of coping strategies women develop in their life courses. Whether women are able to combine various form of work or not depends on the objective and subjective possibilities to deal with controversial life conditions. The fact that women's work is an ensemble of different social practices does not only imply double or triple burden, but also the capability to endure contradictory demands. So the burden of women has a quantitative side (domestic work plus child care plus paid work) and a qualitative side. On a qualitative level, time pressure and the necessity to change priorities when switching between different working places is an extremely hard psychological effort, e.g. attitudes concerning child care differ deeply from demands of performance required in a factory or a firm. In the first case you must have the ability to let time flow playing with the kids, in the second case you are not allowed to waste time.

A special conflict in women's work biographies is discontinuity. Women more often are forced to interrupt their careers, because there are phases where duties in the family are prevalent. Although the unemployment rate of men is increasing in countries where male dominated industries (e.g. mining and steel industries) have been abolished, we can recognize that women more often are fired or put off to a lower position when paid work is generally shrinking.

Changes in the ensemble of women's social activities and shifts of their positions in the labor market, unemployment and migration are evident indicators of alterations due to national and international economic, political and cultural developments. We have a lot of data which prove such alterations. But they are aggregated on such a high level of objectivation that they are too abstract to see the conflicts these changes cause.

The balances women have built up in the past while dealing with domestic unpaid and market-mediated work have to be deconstructed and reconstructed when alterations in the combination of their social activities occur. Shifting from areas of the 
formal to the informal market, from highly qualified jobs to less qualified occupations does not only touch income and social prestige. In any case, a revaluation of positive and negative aspects within the new situation has to be undertaken in order to regain routine. So the need to reorganize balances in changing constellations is a challenge and a strain in women's biographies.

I draw the following conclusions from these considerations: only if we know something about the personal importance the different forms of work have in women's lives, only if we know in which ways women assess their divergent practices and how they find criteria defining pro and contra in each part of their work, can we look - together with them - for measures to improve their living conditions.

\section{CONTRADICTION AND AMBIVALENCE: AN APPROACH TO UNDERSTANDING WOMEN'S WORK BIOGRAPHIES}

The following approach is won by doing biographical studies. Between 1980 and 1986 I made - in cooperation with colleagues and students - 60 in-depth-interviews with working class women (Becker-Schmidt et al., 1982, 1983, 1984, 1985).

Some years later I worked out together with Angelika Wetterer a similar approach by interviewing female and male social scientists.(Becker-Schmidt \& Wetterer, 1990). Christel Schachtner used the so-called "Hannover Ansatz" to understand the conflicts of female and male computer programmers (Schachtner, 1993). Later our approach was used to guide a gender oriented study in the Life History Project at University of Roskilde, Denmark (Weber, 1995). One phenomenon, we found out, corresponds with results of other independent studies. Beyond class and country specific constellations one common trait you can see is that women react with ambivalence to contradictory demands they are confronted with in paid and unpaid work. They assess the different forms of work by comparing and contrasting them. The deficits experienced in the private sphere are compensated by experiences in the public sphere and vice versa. I will give you three examples.

A working class woman I interviewed some years ago articulated a dilemma she cannot solve. She wants to have a family and to participate in the labor force at the same time. She said: "Only one kind of work is too little, the combination of paid and unpaid work is too much". Although her working place (putting together little thin plates, which form a piece for television receivers) is extremely monotonous and restricted, the idea of quitting the job makes her nervous. It is not only the money she cannot renounce. There are intrinsic motivations which drive her to persevere with the working place in the factory. She loves her little daughter and seems to have a good relationship to her husband. "But if I would stay every day at home without my colleagues, without the feeling that I am a good worker and co-worker I would get depressive". She hates the time pressure in the factory, but she likes the possibility to assess her work by holding the norm. For her it is a satisfying feeling that she has produced the number of pieces she has to produce in a shift. "You know, 
I can see what I have done, I can compare my performance with the performances of the others - at home nobody comes and gives me a feedback for my work. You have cleaned a room and after some time it is dirty again. That's boring". Housework is endless. She criticizes the gender segregation in the factory. "All our leading hands are men. I think that's not fair. I am as competent as they are". When her husband proposes to buy a new TV, she makes the decision. Her comment: "TV - that's my thing". She appreciates the freedom at home, to have some self-determination: "When I see the laundry, I can say - oh, today I am not in the mood to iron, I will do it tomorrow. In the factory that is impossible. On the other side: when I leave my firm, all work there is done. When I come home and see the laundry from yesterday, I think: "If you don't do the work now, the household will become a mess". She is angry that she has to take more responsibility for the domestic work than her husband. Gender-based division of work very often causes conflicts. "I cooked a soup, so that he and our daughter had something to eat, when my mother could not be at home at noon. But then he burned the soup. So next time I had to write a note and put it next to the kitchen-range: "Please, do stir".

Monika Goldmann and Ursula Muller had interviews with sales-women. For them time pressure is also the worst stress. "When I come home, I am so exhausted that I need regeneration time for me. But then there are my husband and my child. And they keep me busy. So I ask myself, whether I should switch to a part-time job". An extremely long work day, bad regulation of breaks, bad climatic conditions, the need to stand the whole day - those are the burdens sales women have to bear. On the other side, they like the interaction and communication with the clients. "To find something for them they like is a real pleasure". In the field of selling we can see special conflicts: the pressure to be polite to clients with bad behavior and the obligation to sell things even knowing that they do not fit to the clients.

Ambivalence is the result of these contradictions. The positive experiences, contrasted with the isolation at home, stimulate the desire to hold onto the job. The negative experiences nourish the wish to stay at home (Goldmann \& Müller, 1986). Christel Schachtner pointed out another ambiguity which programmers articulated. They are proud to fulfill a creative profession. They like to develop programs suitable for their clients. They are fond of the logical procedures they have to deal with. Team work is highly valued. But there is always the fear of not catching new developments and becoming old-fashioned. Team work and competition lay very close together. Female and male programmers are threatened by the next generation, which is younger and fitter than them. Female programmers are aware of a special problem: the effects of "deformations professionelles". They recognize the temptation to handle private problems with the same logic as computer programs.

\section{THEORETICAL AND METHODOLOGICAL CONSIDERATIONS}

Before representing a summary of results won in studies dealing with women's work biographies, I want to mention some theoretical and methodological requirements. 
1. We have to avoid a theoretical short-coming, when we want to bring together socio-economic conditions and cultural traditions which frame women's indoor and outdoor work (capitalist norms of performance, gender-based division and segregation of work, unequal assessment of female and male social activities) and the psychic dynamics which unroll in view of attracting and deterring dimensions of labor. Although both levels - the objective and the subjective one - are reciprocally mediated, they do not follow the same logic. We cannot grasp contradictions and incompatible issues which are specific for the outer and the inner realities of a person, if we derive subjective reactions directly from objective constellations or if we see objective conditions without any relation to human actions.

2. We have to take into consideration breaks and imbalances in biographical processes.

3. Similar living conditions do not necessarily imply similar psychological reactions. So we have to search for analogies and deviations with the same attention while studying the work experiences of divergent social groups of women. Ambivalence seems to be a common trait in this field. But the pro and contra, which give the different forms of work their special weight, varies from case to case and the disposition of women to cope with ambiguity differs from person to person as well. One woman may hold together negative and positive aspects of her various social activities following her experience that staying at home is too onedimensional for her. Another may split her ambivalent feelings by forgetting the pressure of paid work at home or letting behind her family troubles while working in the public sphere. A third may harmonize the pain of double burden in order to stick to an internalized double orientation. A fourth may give more weight to the negative dimensions of professional work just to get rid of the impression of being tom up. And we know situations in developing countries where the gaps between processes of modernization in the market-mediated world and the traditional structures in religion and family are so insuperable that women perish who try to bridge them. Those divergences depend on country, class and ethnic specific contexts as well as on socio psychological back-grounds. So we cannot construct a universal theory or develop an omniscient compendium of empirical data which represent all kinds of biographies. But we can conceptualize relatively complex models which are suitable for an exemplary approach and which are open for modifications forced by comparison.

4. We have to break with the idea of "identical individuality". This construction belongs to the European philosophy which is signed by andro-centric and bourgeois concepts of a rational subject which masters reality. We have to see that even when individuals do have the feeling of personal continuity and undividedness their personality is stamped by non-identity: there is no consciousness without unconsciousness; we are often confronted with a divided will; we have to give up plans we have identified with and to cope with unfulfilled wishes. Beyond this: 
subjects don't want to be simply and solely individuals. They need communities, connections and forms of cooperation.

5. "Work" in the sense of "living labor" has another meaning for human beings who want to be active in public spheres than for managements which reduce "living labor" to an exploitative source of profit. Capitalist rules pervert cooperation into competition. The organization of labor has to serve the accumulation lof surplus value. Of course, people work for money. They are instrumentalized for money and they instrumentalize themselves for money. That's unavoidable in marketmediated world-systems. But we should not oversee intrinsic motivations which are addressed to work. Even under work conditions with alienating effects, certain implications of "living labor" cannot be totally suppressed": motion and emotion stimulated by corporeality and practical-communicative spirits. Production and services done for others are connected with the idea of consumption, not with the intention of profit making.

So remnants of liveliness and social commitment survive. These moments of human potentials paradoxically support an organization of work which requires subordination. This reflection emphasizing the divergent importance of labor for employees in comparison with employers is especially important for the understanding of women's work.

As their social activities are embedded in private and public contexts there is a constant flow of meanings loading both forms of work reciprocally with hopes and disappointments. This reciprocal loading is nourished by the changes between the indoor and outdoor working places and the memory of activities performed in former life phases.

Domestic tasks, subsistence work and child care include corporeality and community - at least under the condition, that community is not reduced to the core of a two generation family, but encompasses a wider horizon of kinship and neighborhood. Work organized in such contexts has its own weight as long as it secures the existence of a family. But modernization and rationalization which hallmark globalization processes do not only alter the labor market. These trends penetrate into privacy, too. The family loses more and more of its former functions: production of goods, socialization of the next generation after childhood, connecting the private with the public in acts of hospitality, mediation of cultural practices. On the labor market "living work" has become a commodity reified as other things. But in comparison with domestic work it is paid and gives the wage-earner the role of a bread-winner.

So the prestige of domestic work is weakened. This development provokes women's decision to look for market-mediated work which promises a salary, recognition as a co-worker, as a producer of goods for a common use and as a member of a public space. 
These aspirations rush together with the rules of profit oriented labor: limitation of corporeality, regulation of sensuality, fragmentation of actions. But these experiences lose their harshness in comparison to the degradation of women as housewives, their isolation at home and their dependence on the bread-winner.

The discrepancies between expectations and the shocking reality may be especially hard in contexts of migration or getaways from rural to urban areas with different work traditions.

Let me finish these general reflections with a last methodological consideration.

If we want to acknowledge work experiences women make going from one status passage to the other and switching between different working places, then we should let them be the experts of their everyday lives. That means: we have to listen to them and not to follow our own ideas constructed through the optics of lenses which are spoiled by otherness. Self-reflection and empathy are required to overcome this bias. Scientists have to bridge the gap between theoretical and methodological knowledge, which is necessary for the conceptualization of an investigation, and the experiences of those they want to interrogate

Another epistemological claim is a thorough concept of the questionnaire guiding the in-depth interviews. It must be open for all aspects of domestic and professional work including their reciprocal relations.

There is a tendency in the traditional main-stream of social research, which is oriented around the principles of natural science, to look for consistent results. The devise is "either/or". Contradictory comments seem to be unreliable. But in view of women's living conditions, which are characterized by controversial structures and demands, we must be aware of unstable reactions that correspond incompatibilities. So the interviews must be conducted to allow women to express objective inconsistencies in a contradictory way. They should have the opportunity to change their perceptions according to altering contexts and to see situations from different angles.

So a questionnaire suitable for women's work experiences has to combine three approaches. First: in retrospect, we have to grasp the influences of the past. Former events have another meaning seen from the present balance than they did years ago. Second: It is necessary to focus the interviews on the most important issues which mark women's present work life: family and professional career. But - and that's the third methodological requirement - these centers of investigation cannot be treated as isolated parts, discussed one after the other. As they are interrelated within the life courses and as experiences alter their content following altering contexts women must be encouraged to change their perspectives. Working women talk about domestic tasks in another way when they see them from the angle of outdoor labor and not only within the frame "family". And vice versa: positive and negative aspects of market-mediated labor gain other facets when discussed in the context of domestic work than within the thematic center "professional performances and demands". The ambivalences which occur are results of two psychodynamic processes: the one can 
be seen as a reaction to immanent frictions women are confronted with in all their work areas; the other is shaped by contrasting them. Women try to bargain the costs and advantages of the two possible decisions: to stay at home or to combine paid and unpaid work.

Women's Work: A Model for the Analysis of Complex and Multi-dimensional Social Problems

Let us remember the connections women's work biographies are embedded in.

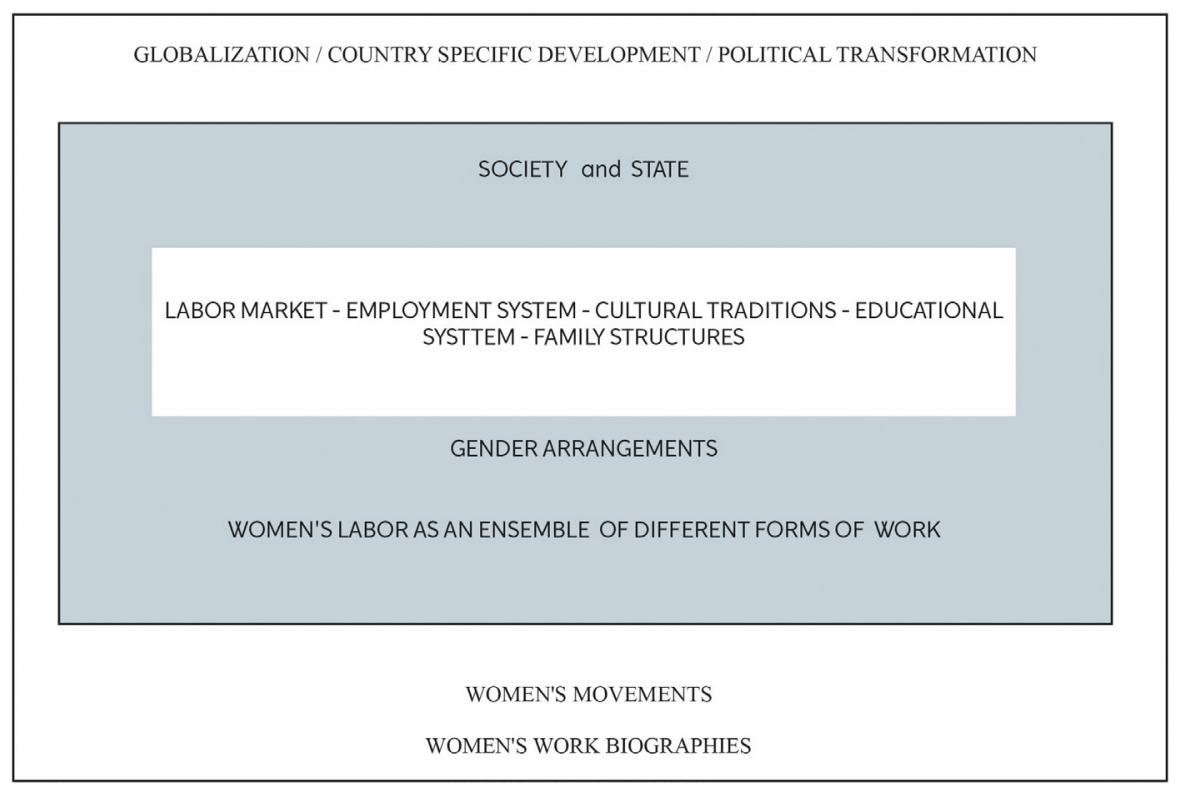

Figure 4.1. A summarizing model

In the following passages I want to show interdependencies between objective and subjective life conditions and the psychodynamics due to discrepancies in both contexts.

In order not to overcharge the formalized summary, I chose a simple model which deals only with two dimensions of women's work: domestic and work in firms.

I will begin from the perspective of a present stage and add then a short biographical retrospective.

I have pointed out the contradictions women have to cope with within the family and professional work. 
Let's repeat the incompatible issues of firms.

In all profit-oriented firms, two contradictory claims can be found:

accumulation of profit (dimension of quantity)

Production of commodities for the consumers (dimension of quality)

This implies two other contradictions on the level of work performance

The organization of labor has a strict time regulation, but requires through performances

high outpur under timepressure $\leftrightarrow$ no waste, skilled work

The profit-oriented arrangement of cooperation causes

competition (challenge of personal ambitions) solidarity (reciprocal) help to lessen bad working conditions

The structural contradictions lying on a more abstract level are recognized via controversial demands. They cause ambivalence.

The institution "family" which frames domestic work is marked by structural contradictions, too.

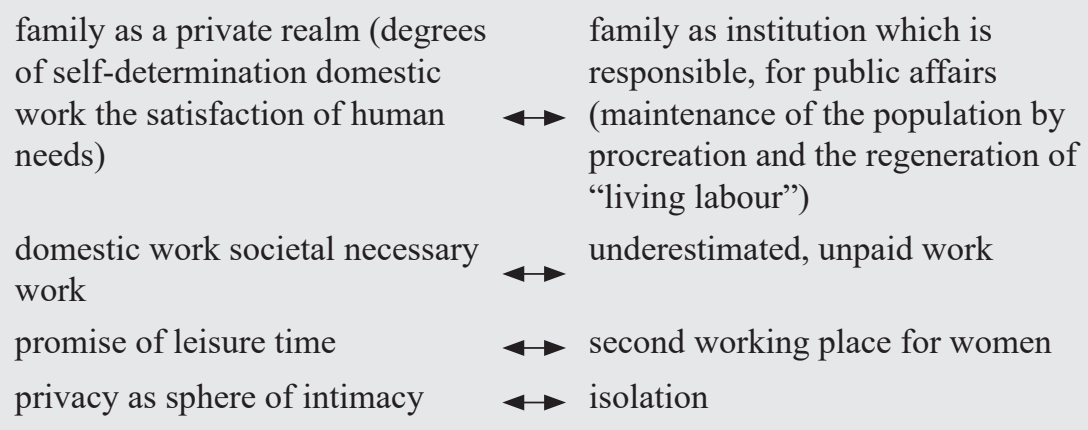

In the private sphere women are also confronted with controversial demands due to structural contradictions which cause ambivalences. 


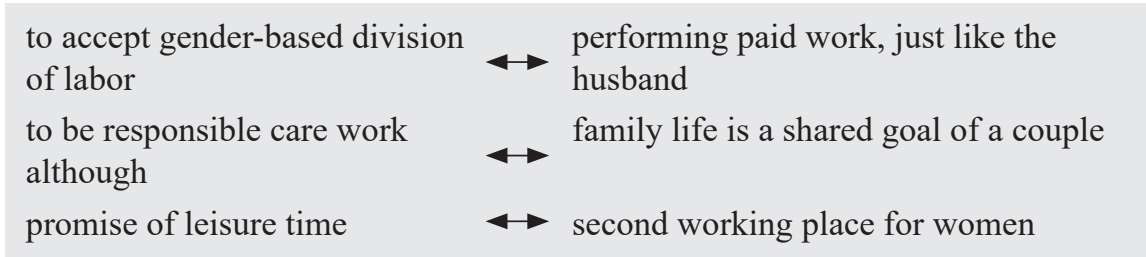

We have to be aware of two dimensions of contradictions:

We have recognized incompatibilities within family and firm, but also those between the differently structured institutions: exploitation of "living labor"/ regeneration of life; paid/unpaid work; private/public.

So we can reconstruct the positive and negative aspects of ambivalences.

\section{Outdoor work means}

\begin{tabular}{|c|c|}
\hline time pressure & $\leftrightarrow$ feeling to be a good worker \\
\hline exhausting work & $\leftrightarrow \begin{array}{l}\text { transparence of conditions and work } \\
\text { norms }\end{array}$ \\
\hline $\begin{array}{l}\text { indifference against } \\
\text { individuality }\end{array}$ & acknowledgement salary \\
\hline competition & $\leftrightarrow$ cooperation, communication \\
\hline
\end{tabular}

\section{Indoor work means}

being part of relationships
$\begin{aligned} & \text { domestic work is vanishing while it is } \\ & \text { done }\end{aligned}$
satisfying human needs
being one's own mastress

In addition we have to consider the following dynamics.

First: experiences made in the firm affect women's attitudes towards the family and vice versa. I quote the working class woman we have already noticed to illustrate this fact. "This morning I said to my boss: 'I can't stand your treatment of me. Do you deal with your wife at home in the same manner? I don't think you would dare". Interactions taking place in the private sphere serve as measurement for human behavior in the firm. And vice versa: forms of recognition experienced in the firm are standards for behavior in the family. My interviewee encounters her husband with a self-confidence she has won in the firm. One day he didn't want to help her 
clean the dishes. She shouted: "If you want to play the pascha here, you will see no penny of my earnings in the future".

Second: there is a correspondence between the evaluation of paid and unpaid work which is faned by comparison and contrast. The results of comparison and contrasting decide on the weight the different forms of work are assessed with.

\section{AN EXTRACT FROM A CASE STUDY: "DEFERRED ACTION"}

When interpreting interviews I had with working women I stumbled upon a mechanism to deal with disguised conflicts which belonged to former life phases. The conflicts had to do with dreams or wishes which could not be realized at the time they occurred. Although they were of great relevance for the interviewed persons they disappeared. But by reading their life stories very thoroughly I could find traces of them in other life passages. The wishes had changed, but certain motivations were re-conceivable. I knew this phenomenon from Freud. He called it "Umschrift" ("retroactive interpretation" or "transcription") and characterized it as follows: it is a mental operation through which past experiences, impressions and desires, which must be suppressed out of inner or outer reasons in the life span when they emerged, are reactivated later on. That what seemed to be lost reappears in a new significance and in new psychic dimensions. It is as if the dreams and desires had wintered in the realm of the unconsciousness and waited there until the time is ripe for their fulfilment. The wishes do not reappear in the old form but better adjusted to the outer and inner reality. Freud assumed that there are situations in our biographies in which we do not understand why we are not allowed to do this or that. So we have no target for resistance. Growing up, we learn to cope with obstacles. The conflicts which could not be solved in former life phases can be solved later on and the suppressed desires can then be accepted. I adhere to Freud's explanation that experiences are reinterpreted retrospectively when a state of consciousness or a context of meaning has been established which allows us a more productive exposition with the old conflict. Freud invented for this psychic operation the notion "Nachtraglichkeit" ("deferred action").

The mechanism of deferred action makes new assessments possible and in turn also releases new impulses to act. From the present falls light into the past and the energy bound in the unconsciousness is freed for the future.

I will give you an example taken from a case study.

Mrs. X dreamt in her childhood: as an adult she would be a driver of a bus. She would be an employee of a tourist agency and drive people through foreign countries.

The dream disappeared in school time. Her teacher said: "That's no profession for a girl".

Mrs. X did not understand why a woman should not be able to drive a bus. In this age gender based segregation of work was not yet mentioned. But as she recognized that her dream was an offence to her teacher she forgot about it. But the wishes 
which had driven the dream stayed in her, unconsciously. The desire to move, to have adventures and to be free remained unimpressed.

As a teenager, she dreamt of having a motorcar, a black leather suit and a boyfriend sitting on the back seat.

When she had a boyfriend who was accepted by her parents her father financed a motorbike. But the friend drove the motorbike and after an accident the fun was over. The dream of a motorcar representing the old desires had to be deduced to a motorbike. And Mrs. X made a new experience which touched a former disappointment: Women are not allowed to do the same as men do. There is a genderorder: not women but men drive busses and motorcars. This knowledge transformed her drives: the wish to transgress gender-orders joined the desire to be mobile, to experience motion and adventures.

After her schooling, Mrs. X worked in a car factory. After two years of piece work, she passed the park of transporter vehicles. She decided to get her driver license for a fork-lift truck. She got it. But as she was a woman she was only allowed to drive a little fork-lift truck. She convinced her colleagues who worked together with her in the park to let her drive a bigger one from time to time. One day she appeared in her boss' office and showed a new license: one for a bigger transporter. At last she got the permission to drive it.

We see: psychoanalytically oriented social science can help to find hidden potentials in women's biographies which can be reactivated and which can stimulate motivations concerning vocational training or emancipation from patriarchal power structures within the private and public sphere. When we wish to encourage women to go their own way in an independent manner, it is perhaps helpful to know that dreams constituted in former times, let's say childhood, are not lost when women are forced to give them up. They are laid down in a realm where they are not controlled by the principles of reality: that's the psychic space of unconsciousness. As the unconsciousness holds contact with the consciousness, old dreams can be modified with the development of a person. So I think that dreams are relevant forces for the will to change unjust life conditions.

\section{NOTE}

1 This is no anthropological remark. We know from the Nazi-regime, that the human basis of living labor can be denied to a degree that exploitation implies killing. But the capitalist has to respect liveliness. As "living labor" is an instrument of profit, it needs - like a machine - some care.

\section{REFERENCES}

Becker-Schmidt, R. (1990). Umschrift und Nachtraglichkeit in Biographien von Soziologinnen. In I. Sommerkorn (Ed.), Lehren und Lernen in der Soziologie heute. Aktuelle Fragen zu einem alten Problem (pp. 100-126.). Berlin: Sigma Rainer Bohm Verlag.

Becker-Schmidt, R., Brandes-Erlhoff, U., Knapp, G. A., Rumpf, M., \& Schmidt, B. (1982). Nicht wir haben die Minuten, die Minuten haben uns. Bonn: Verlag Neue Gesellschaft. 
Becker-Schmidt, R., \& Knapp, G. A. (1986). Arbeiterkinder gestern, Arbeiterkinder heute. Bonn: Verlag Neue Gesellschaft.

Becker-Schmidt, R. et al. (1983). Arbeitsleben - Lebensarbeit. Bonn: Verlag Neue Gesellschaft.

Becker-Schmidt, R. et al. (1984). Eines ist zu wenig - beides ist zu viel. Bonn: Verlag Neue Gesellschaft.

Goldmann, M., \& Müller, U. (1986). Junge Frauen im Verkaufsberuf. Berufliche Sozialisation, Arbeitsund Lebensperspektiven. Berlin/Köln/Mainz: Schriftenreihe des Bundseministers für Jugend, Frauen und Familie.

Schachtner, C. (1993). Geistmaschine. Faszination und Provokation am Computer. Frankfurt a.M.: Suhrkamp.

Weber, K. (1995). Ambivalens og Erfaring (Dissertation). Roskilde University.

Wetterer, A. (1990). Frauenthemen und Themen von Frauen in der Soziologielehre. In I. Sommerkorn (Ed.), Lehren und Lernen in der Soziologie heute ... (pp. 127-1467). Berlin: Sigma Rainer Bohm Verlag. 